\title{
Термины родства у родовой группы монгушей с. Аянгаты Барун-Хемчикского района
}

\author{
Надежда Д. Сувандии \\ Тувинский государственный университет, Российская Федерация
}

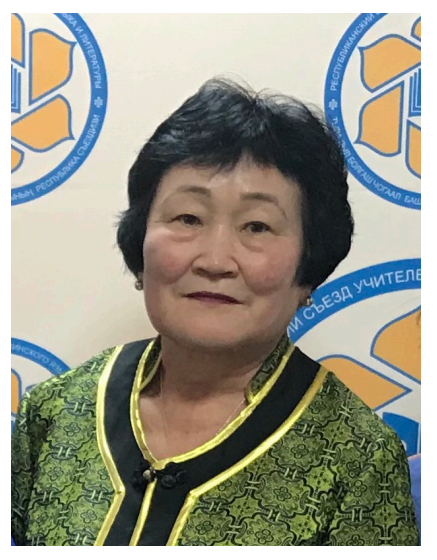

В статье рассматривается терминология родства, родственных отношений тувинцев на примере терминов, которые использует родственная группа монгуш, выходиев сумона Аянгаты Барун-Хемчикского района, которые сами называют свою родственную общность помимо төрел аймак 'родовая группа' термином төрелдөргүл монгуштар 'родня монгушей'. Материал был собран автором во время одного из родовых сборов 2021 г., который состоялся для проведения суг бажының дагылгазы - 'обряда освящения начала источника', в том числе с помощью интервью у представителей группы - родственников.

Терминология в статье приводится по группам: общие термины родства, отдельные термины для обозначения кровных родственников и родственников по браку. Собранные термины позволяют увидеть, что для старшего поколения имеет значение традиционная терминология, которая зафиксирована в словарях, изучена исследователями. Молодежь и дети используют много русских терминов. Помимо этого, отмечается группа терминов - новообразований. Современные люди не удовлетворяются устоявшимися названиями, не стараются соблюдать нормы, предпочитают использовать более удобные или интересные для них слова, а иногда и с уменьшительно-ласкательными окончаниями.

Терминология родства одной родственной группы западных тувинцев сама по себе представляет исследовательский интерес, так как показывает и общетувинские тенденции языковых процессов, и определенные локальные особенности. Тем не менее, для общей картины следует расширить исследовательское поле и включить в него и другие родственные группы.

Ключевые слова: терминология родства; монгуш; тувинцы; Тува; тувинский язык; билингвизм; родство; родственная группа; родня

Подготовлено при финансовой поддержке Российского научного фонда в рамках научного проекта «Тезаурус этнической культуры в XXI веке: проблемы исследования и сохранения (на примере тувинской культуры)» (грант № 21-18-00246).

Для цитирования:

Сувандии Н. Д. Термины родства у родовой группы монгушей с. Аянгаты Барун-Хемчикского района // Новые исследования Тувы. 2021, № 4. C. 22-30. DOI: https://www.doi.org/10.25178/nit.2021.4.2

Сувандии Надежда Дарыевна - кандидат филологических наук, старший научный сотрудник лаборатории этнологии и лингвокультурологии; декан филологического факультета Тувинского государственного университета. Адрес: 667000, Россия, г. Кызыл, ул. Монгуша Сата, д. 9, лит. В, каб. 107. Тел.: +7 (923) 268-93-69. Эл. адpec: suvandiin@mail.ru

SUVANDII, Nadezhda Daryevna, Candidate of Philology, Dean, Philological Faculty, Tuvan State University. Postal address: Office 107, Letter B, 9 Mongusha Sata St., 667000 Kyzyl, Russian Federation. Tel.: +7(923) 268-93-69. E-mail: suvandiin@mail.ru 


\title{
Kinship Terms of the Mongush Tribal Group of the Village of Ayangaty in the Barun-Khemchik District
}

\author{
Nadezhda D. Suvandii \\ Tuvan State University, Russian Federation
}

\begin{abstract}
The article examines the terminology of kinship and blood relations of the Tuvans drawing on the case of terms used by the Mongush tribal group, the natives of the Sumon of Ayangata in the Barun-Khemchik district. They call their kinship community not only 'terel aimag' ('tribal group') but also by the term 'terel-dergul mongushtar' ('relatives of the Mongush people'). The material was collected by the author during one of the clannish gatherings in 2021, which was held in order to perform the sug bazhyn dagylgazy - the 'rite of consecration of the spring's source', including through interviews with representatives of the group, i.e. relatives.

In the article, the terminology is presented in the following groups: general terms of kinship, special terms for designating blood relatives and relatives-in-law. The collected terms allow us to see that traditional terminology is important for the older generation. It is included in dictionaries and studied by researchers. Young people and children use many Russian terms. In addition, there is a group of neologisms. Modern people are not satisfied with established designations. They do not try to comply with the norms and prefer to use words that are more convenient or interesting to them, and sometimes those that have diminutive endings.

The kinship terminology of one kin group of the Western Tuvans is of research interest per se, because it shows both the general Tuvan trends in the language development and certain local features. Nevertheless, in order to have the overall picture, it is necessary to expand the research field and include other kin groups in it.
\end{abstract}

Keywords: kinship terminology; Mongush; Tuvans; Tuva; Tuvan language; bilingualism; kinship; kinship group; extended family

\section{Financing}

The article was prepared with financial support from the Russian Science Foundation within the framework of the research project "Thesaurus of Ethnic Culture in the 21st Century: Problems of Study and Preservation (The Case of Tuvan Culture)" (grant No. 21-18-00246).

For citation:

Suvandii N. D. Terminy rodstva u rodovoi gruppy mongushei s. Aiangaty Barun-Khemchikskogo raiona [Kinship Terms of the Mongush Tribal Group of the Village of Ayangaty in the Barun-Khemchik District]. New Research of Tuva, 2021, no. 4, pp. 22-30. (In Russ.). DOI: https://www.doi.org/10.25178/nit.2021.4.2

\section{Введение}

Одним из древнейших пластов в лексической системе тувинского языка является терминология родства - обособленная лексико-семантическая группа, состоящая в основном из имен существительных. Она была основательно изучена Л. С. Кара-оол в монографии на основе кандидатской диссертации, где автор рассмотрела традиционные термины кровного родства, термины свойства и понятия, примыкающие к терминологии родства (Кара-оол, 2004, 2006). Однако, как и сама система родства, так и ее терминология - исторически изменчивы. В связи с развитием в Туве билингвизма, в основном тувинско-русского, но уже имеющего тенденцию к изменению на русско-тувинский (Ламажаa, 2021b: 184), тувинцы в своей речи нередко используют русские заимствования, в том числе в терминах родства.

Поэтому исследовательский интерес представляет современное состояние терминологии в том виде, в котором она функционирует у носителей языка и субъектов самой культуры. При этом, учитывая и то, что тувинский язык имеет диалекты (Чадамба, 2013) и этот факт отражается на диалектных формах терминов родства (Кара-оол, 2006: 15), очевидно, что вопросы функционирования терминологии важно рассматривать на отдельных ареалах, диалектах. 
Более того, подчеркнем, что интерес может представлять и терминология, которая используется отдельными родственными группами тувинцев. Актуальность этого аспекта связана с тем, что с начала 2000-х годов увеличилась интенсивность родовых движений современных тувинцев (Ламажаа, 2021с), усилилось значение в их жизни родственных групп (аймак, төрел аймак, төрел бөлүк, төрел-дөргүл), а также в целом родственных связей и отношений (Ламажаа, 2021a).

Учитывая все эти обстоятельства, целью данной статьи является выявление терминологии родства и родственных отношений у аймака монгушей - родственной группы монгуш, выходцев сумона Аянгаты Барун-Хемчикского района.

Для достижения поставленной цели решались следующие задачи:

- проанализировать основные тенденции научных исследований терминологии родства у тувинцев,

- систематизировать термины общего родства, употребляемые среди представителей родовой группы монгуш;

- систематизировать термины кровного родства, означающего конкретных близких родственников, которые используют монгуши,

- систематизировать термины родства по браку.

Источником исследования послужили материалы, собранные автором в 2021 г. во время проведения обряда дагылга родственной группы монгушей (Дагылга: тувинские ... , 2021: 14-19, 86-91), членом которого является сам автор; во время работы с информантами - представителями данной общности. Для сравнения с традиционной системой терминологии также необходимо было опираться на материалы упомянутой монографии Л. С. Кара-оол (Кара-оол, 2006), тем не менее учитывались и публикации других авторов.

\section{Этнография и филология}

Если взглянуть на публикации по нашей теме и годы их появления, то мы можем увидеть, что изучение терминологии родства в тувинском языке сначала было связано, в основном, с этнографическим изучением тувинцев, начиная с рубежа XIX - XX вв., а затем выделилось в отдельное направление исследований филологов.

Так, термины родства у тувинцев рассматривались в работах путешественников и этнографов рубежа XIX-XX вв. (Яковлев, 1900; Кон, 1934). Автор первой фундаментальной грамматики тувинского языка Н. Ф. Катанов тогда же собрал и систематизировал более 50 терминов родства (Катанов, 1903). После этого уже спустя полвека изучением терминов родственных отношений начал заниматься известный этнограф, востоковед-тюрколог С. И. Вайнштейн. Он подчеркнул некоторые особые черты тувинской системы родства, также представил основные термины родства западного диалекта тувинского языка (Вайнштейн, 1961, 1969, 1989). Л. П. Потапов в своей работе по этнографии тувинцев также привел номенклатуру некоторых основных терминов родства (Потапов, 1969).

В этом же русле выступают труды исследователя тувинской культуры М. Б. Кенин-Лопсан, который одновременно с освещением нюансов народного этикета тувинцев, также и поднял терминологию родства, начиная с названий родовых групп, заканчивая их правильным произношением (КенинЛопсан, 1994: 53-65).

Далее терминология родства получила развитие в филологических трудах. Так, А. А. Бурыкин и Н. И. Летягина дали не только описание терминов родства тувинцев, но и остановились на некоторых теоретических вопросах данной группы слов (Бурыкин, Летягина, 1999). Е. М. Куулар рассмотрела функционирование терминов родства на юго-восточном диалекте тувинского языка, являющимся одним из специфичных в связи с тем, что территория носителей которого граничит с Монголией и немало заимствованных наименований из монгольского языка (Куулар, 2000).

Систематизация терминов родства была представлена затем в исследованиях Л. С. Кара-оол, о чем уже упомянуто выше. Л. С. Кара-оол описала термины кровного родства, родства по браку, а также понятия, примыкающие к терминологии родства (Кара-оол, 2006). Филолог отмечает, что термины родства, являясь важным историко-этнографическим источником, представляют большой интерес не только при изучении истории и этногенеза народа, но и с лингвистической точки зрения, при исследовании языка в сравнительно-историческом плане, как материал для его исторической грамматики и лексикологии (там же: 16). 
C начала XXI века в связи с трансформациями этносоциальных и этнокультурных явлений тувинского общества, проблематика изменения в том числе терминологии родства побуждает рассматривать эти вопросы в связи с общими этнологическими исследованиями. Так, французский ученый Ш. Степанофф рассмотрел существенные изменения в разных аспектах родства таких, как филиация, норма брачного союза и терминология (Степанофф, 2009).

Сотрудники лаборатории этнологии и лингвокультурологии Тувинского госуниверситета также отмечают, что родовые связи и родовые отношения остались важными для тувинцев на протяжении всего XX века, несмотря на социально-трансформационные процессы и изменения в культурной жизни. Концепт төрел 'родственник' рассматривается как единица ментального образования, в котором отражено миропредставление носителей культуры, присутствующее в языковом сознании (Кужугет и др., 2019: 150). Соответственно, терминология родства входит в поле внимания исследователей наравне с этнологическими работами (Дагылга: тувинские ..., 2021). Это слово, по мнению Л. С. Караоол, является заимствованным из монгольского языка термином обобщенного характера, который не входит в номенклатуру терминов родства, но характеризует категорию или разряд родственных отношений (Кара-оол, 2004: 21).

Тем самым, изучение терминов родственных отношений у отдельно взятой родственной группы восполнит пробел, имеющий место быть не только в лингвистических, но и этнографических изысканиях.

\section{Общие термины родства}

Терминология родства особенно заметно выявляется при встрече родственников, когда они прямо обращаются к представителям разных семей, поколений. Встречи расширенного круга родства сегодня в Туве происходят на различных обрядах, и интереснее всего это наблюдать во время родовых сборов чыыштар для проведения дагылга - обрядов освещения природных объектов, которые стали активно и регулярно проводиться с 2000-х годов.

Точно также с 2000-х годов родственная группа монгуштар, т. е. монгушей төрел-дөргүл монгуштар 'родня монгуши' ежегодно начали проводить обряд суг бажының дагылгазы - 'обряд освящения начала источника'. Основной причиной для того, чтобы монгуши начали проводить данный обряд, стала смерть сразу шестерых близких родственников - потомков нашего дедушки Намчыла Чадамбаевича Монгуша (1896-1961), которые произошли друг за другом в 2000 г. Верховный шаман Тувы Сайлык-оол Иванович Канчыыр-оол, к которому обратились за помощью опечаленные люди, пояснил, что им надо срочно начать проводить обряды, поклониться хозяевам родового места, иначе потери могут увеличиться (Дагылга: тувинские ..., 2021: 14-15). Так и началась современная история обрядов монгушей в местности Кара-Мажалык у села Аянгаты Барун-Хемчикского района.

11 июня 2021 г. родственная группа монгушей проводила очередной обряд суг бажының дагылгазы. На него собралась большая группа родственников - более 60 человек. В прошлом 2020 году они не могли увидеться в связи с распространением COVID-19 и режима самоизоляции, пришедшегося именно на сезон проведения этих обрядов в Туве.

Как обычно, во время встреч после долгого перерыва родственники с большим удовольствием общаются между собой, используя в обращении друг к другу различные термины родства.

Они также называют свою общность төрел аймак 'родовая группа', но, помимо этого термина, распространенным среди собравшихся родственников являются слова төрел - 'родственник', 'род’ / 'родовой’ (Тувинско-русский ..., 1968: 419), төрел-дөргүл - 'родня' (там же: 420). Их произносил каждый подъехавший участник обряда. Более того, внуки нашего дедушки Намчыл Чадамбаевича, которым уже более 50-70 лет, пытаются донести до своих детей и внуков информацию о близком родстве собравшихся, о том, что все мы - төрелдер 'родственники' дөргүл-төрелдер 'родня'.

Это слово, по мнению Л. С. Кара-оол, является заимствованным из монгольского языка термином обобщенного характера, который не входит в номенклатуру терминов родства, но характеризует категорию или разряд родственных отношений (Кара-оол, 2004: 21).

Родственники для тувинцев считаются поддержкой, опорой по жизни и не зря наши предки учили своих детей всегда поддерживать связь с родственниками, никогда не забывать, что төрелдер - это самые близкие люди в жизни. Эта истина заложена и в народных поговорках, до сих пор исполь- 
зующихся людьми для объяснения ее сути. Например, как говорят наши информаторы, Төрел билбес кижи дөңгур көк буга бооп төрүттүнер - 'Не знающий своего рода человек переродится комолым быком (в следующей жизни)'; Төөгү билбес төөрээр, төрел билбес түрээр - 'Не знающий историю будет заблуждаться, не знающий родни будет побираться' ${ }^{\text {. }}$

При этом для обозначения группы родственников, общности родственников самым распространенным термином оказался дөргүл-төрел төрел-дөргүл. Во время дагылга многие родственники старшего поколения использовали в своей речи данный термин при указании тех, кто нас окружал в тот момент. Также наша старшая сестра Дамбыра Сесенмаа Дарыевна - самая старшая из всех собравшихся на дагылга - рассказывала молодым, что в жизни тувинцы всегда поддерживали и поддерживают дөргүл-төрел, т. е. свою родню в любых ситуациях: и в горе, и в радостиㄴ.

Как мы установили с коллегами ранее, термин төрел в словарном фонде и тувинской художественной литературе имеет разные формы (Кужугет и др., 2019). В них указывается, что словосочетание төрел-дөргүл представляет собой собирательное существительное (Тувинско-русский ..., 1968: 420). При этом оно имеет большую частотность использования в произведениях тувинской литературы (Кужугет и др., 2019: 152). Помимо сочетания төрел-дөргүл, в тувинском языке также имеются формы төрел бөлүк (родственная группа) и төрел аймак (родственники по одному роду, общее название рода) (там же: 151-152). Каждый термин имеет определенный нюанс, хотя порой на практике тувинцы могут использовать их как синонимы. В нашем случае, полагаем, что родственники группы монгушей, преимущественно используя термин төрел-дөргұл, подчеркивают в первую очередь общий факт родственности семей.

\section{Отдельные термины родства}

Помимо основного термина своей группы родственников, тувинцы используют и термины кровнородственных отношений, которые обозначают отдельно родителей, детей, а также предков и потомков - людей, имеющих одного общего родителя или предка (Кара-оол, 2006: 31).

В нашем случае таковым общим предком все считают Намчыла Чадамбаевича Монгуша, который для нас - меня и моих родных и двоюродных сестер и братьев, является дедушкой. Мы в этом случае говорим кырган-ача кырган-ачай 'дедушка' (Тувинско-русский ..., 1968: 278) и, упоминая его жену Куулар Иликей Чашовну (1898-1943), нашу бабушку, говорим кырган-ава кырган-авай ‘бабушка’ (там же: 278). Это традиционные термины, которые также отмечаются в работе Л. С. Кара-оол (Кара-оол, 2006: 22). Они имеют хождение у представителей төрел-дөргүл монгушей, но только старше 35-40 лет. Молодежь до 35 лет и дети в большей степени уже используют русские термины: бабушка бабуля, бабуль, дедушка деда, дедуля, дедуль и т. д.

К своим родным матери и отцу члены нашей родни в основном обращаются традиционными терминами ава, авам 'мама, моя мать' (Тувинско-русский ..., 1968: 31), ача, ачам 'отец, мой отец' (там же: 77; Кара-оол, 2006: 22). Но уже немало представителей молодого поколения и дети дошкольного и школьного возраста, говоря о родителях, также уже оперируют русскими терминами: мама мам, мамуля, nana nan, nапуля. Дети дошкольного возраста, которые в семье говорили на родном тувинском языке, начиная посещать дошкольные образовательные учреждения, часто переходят на русский язык, в том числе в терминологии родства, обращаясь к своим родственникам.

Своих детей и внуков, по моим наблюдениям, наши старшие родственники в основном называют словами оглум ‘мой сын’ (Тувинско-русский ..., 1968: 313), кызым, уруум ‘дочь, доченька' (там же: 280). Также называют и правнуков, правнучек. Молодое поколение тоже может использовать эти слова, но с русифицированными окончаниями: оглуш оглуушка 'мой сынуля', уруушка урууша 'доченька'. Среди них также немало и тех, кто называет только русскими словами (особенно если это русскотувинские, а не тувинско-русские билингвы, или полностью русскоговорящие тувинцы): сына, сынуля, доча, дочура, доченька. Если в прежние времена бабушки и дедушки называли внуков и внучек теми же словами, что и своих детей, а именно оглум 'мой сын', уруум 'моя дочь', то с 1990-х гг. они стали

\footnotetext{
${ }^{1}$ Кужугет Мария Амын-ооловна, 1955 г.р., род. в с Аянгаты, Барун-Хемчикского района, проживает в г. Кызыл.

${ }^{2}$ Дамбыра Сесенмаа Дарыевна, 1946 г.р., род. в с. Аянгаты, Барун-Хемчикского района, проживает в мест. Ортаа-

Кара-Суг, Кызылского района Республики Тыва.
} 
использовать новообразованное слово уйнук уйнуум 'внук, мой внук'. Как пишет Л. С. Кара-оол, оно было предложено Народным писателем Тувы А. Даржаем (при этом этимологию новообразования так и не удалось установить) и в основном имело хождение в средствах массовой информации республики (Кара-оол, 2006: 96). Как мы видим, слово уже перекочевало в обиход, используется людьми.

Почти в каждой семье у наших монгушей имеется не менее двое детей, за исключением одних двух, у которых по одному ребенку. Для обозначения родных братьев и сестер используются собирательное слово алышкылар ‘братья-сестры’ (Тувинско-русский ..., 1968: 56), также лексемы угбашкылар 'сестры’ (там же: 432) и акышкылар (там же: 51). Для обращения друг к другу они употребляют термины акый 'брат' (там же), угбай 'старшая сестра' (там же: 432), а по отношению к младшим используют термины дуңмам лит. ынам, ынай диал. 'мой младший брат или моя младшая сестра' (там же: 184).

Близких родственников по материнской линии наши дети называют традиционными терминами: даай 'дядя' (там же: 139) и даай-ава даай-авай 'тетя' (там же: 139), хотя бывает, что некоторые представители молодого поколения монгушей обращаются ко всем родственникам терминами русского языка тетя и дядя (Бурыкин, Попов, 2020: 49), что является новой формой обращения молодежи моложе 30 лет.

Так, мы видим поколенческие различия в использовании терминологии, которые показывают тенденцию к русификации используемых терминов родства у новых поколений тувинцев.

\section{Обращения к супругам}

Отдельно следует остановиться на употребляемых среди нашей родовой группы терминах родства, возникших в результате брачных союзов, не состоящих в родственных отношениях (Кара-оол, 2006: $101)$.

Основу брачного союза составляет термин ащак-кадай собир. 'муж с женой, супруги' (Тувинскорусский ... , 1968: 77), который встречается только у старших потомков группы монгушей. Современная молодежь в разговоре употребляет русский термин семья бистиң семья, что уже становится нормой среди представителей молодого поколения. Интересно констатировать, что старшее поколение также стало называть своих супругов на русском языке, подчеркивая наличие у них внуков - дедушка и бабушка ${ }^{1}$, поскольку именно так к ним в первую очередь обращаются внуки.

Термины ашак, ашаа 'муж, мой муж’ (там же: 77) и кадай, кадайым 'моя жена' (там же: 215), по моим наблюдениям, среди наших родственников вообще не употребляются.

Среди пожилых имеют хождение термины демги кижи 'тот человек', бо кижи 'этот человек', өөм ээзи букв. 'хозяин моей юрты - муж’, өөм ишти букв. 'внутренность моей юрты - жена' по отношению к своим женам и мужьям, уругларым авазы букв. 'мать моих детей', уругларым ачазы 'отец моих’2. Использование подобных терминов восходит к традиции табуированного прямого называния родственников, что в свою очередь выражало уважительное отношение к своему мужу или жене (Кенин-Лопсан, 1994: 59-61).

В разговорах невесток старше 50 лет со своими свекровями и свекрами у төрел-дөргұл монгуш употребляются различные слова-термины, когда основным термином считается лексема кунчуг 'свекровь' (Тувинско-русский ..., 1968: 265), бег 'свекор, деверь'. Некоторые наши невестки обращаются словом кунчуум 'моя свекровь', бээм 'мой свекор', что показывает близкое, теплое отношение к родителям мужа. Есть слово кунчууш от слова кунчуг в уменьшительно-ласкательной форме. Большая часть невесток нашего рода употребляет русское слово бабушка, подразумевая обращение к бабушке своих детей, или соответственно дедушка. Редко, но есть и те, кто обращается по имени и отчеству к свекрови, по отношению к дедушкам данное обращение нами не замечено.

Во время сбора материала я также зафиксировала, что невестки и зятья к старшим невесткам и зятьям обращаются как тувинскими терминами угбай 'сестра' или акый 'дядя’, так и русскими - тетя,

${ }^{1}$ Сувандии Аркадий Максимович, 1959 г.р., род. в с. Белдир-Арыг, Тес-Хемского района Республики Тыва, прож. в г. Кызыл.

${ }^{2}$ Монгуш Виктор Бойдуевич, 1938 г.р., род. в с. Аянгаты, Барун-Хемчикского района, проживает в с. Сукпак, Кызылского района Республики Тыва. 
дядя, например, тетя Света, дядя Аркадий'ㅡ, при этом в близких родственных отношениях они с ними не состоят, но относятся к старшим также, как их мужья и жены - как к тете и дяде.

Зятья монгушей между собой используют термин бажа 'свояк' (Тувинско-русский ... , 1968: 83). В общении с родителями и старшими родственниками жен они называют их кат-ие 'теща', катым 'мой тесть'. Замечены единичные случаи, когда зятья обращались к теще кат-ием 'моя теща', что характеризует теплое и близкое отношение его к матери супруги.

Представители родовой группы монгуш, к мужьям и женам своих детей употребляют термины западного диалекта тувинского языка: кеннишке вместо келин 'сноха, невестка' (там же: 237), хүреген вместо күдээ 'зять' (там же: 268). Также распространены слова: чаавай 'невестка' (там же: 503), честей ‘зять' (там же: 529). Также зафиксирован один интересный вариант, когда парни обращаются к зятьям сокращенной формой от честей - чес 'зять'. Такая форма не упоминается ни в словарях, ни в работе Л. С. Кара-оол. На мой вопрос о том, почему они так говорят, мне объяснили, что это означает близкое отношение к ним²

В целом обращения к супругам, к родственникам по браку у монгушей очевидно также имеют тенденцию к русификации, но помимо этого также используются диалектные термины, даже новообразования.

\section{Заключение}

Использующая терминология родства у родственной группы монгушей с. Аянгаты Барун-Хемчикского района в целом, может быть разделена на три группы. Первая группа - традиционная терминология, которая зафиксирована в словарях, изучена исследователями. В основном она используется людьми старшего поколения. Вторая группа - русские термины, которые больше использует молодежь и дети, что отчасти свидетельствует об изменении тувинского билингвизма, грядущих перспективах его смены с тувинско-русского на русско-тувинский. Третья группа - менее малочисленная - новообразования, которые свидетельствуют о том, что современные люди не удовлетворяются устоявшимися названиями, не стараются соблюдать нормы, но иногда предпочитает использовать более удобные или интересные для них слова, а иногда и с уменьшительно-ласкательными окончаниями оглуушка 'сынуля', уруушка 'дочурка', кенниишке 'невестушка'.

Последние примеры к тому же могут быть определенными отличительными признаками этой родственной группы или функционировать в определенном ареале, например, в западной Туве. В общении же родственников со стороны мужа (родственной группы оюн южных - тес-хемских - тувинцев) я такого не встречала.

У наших монгушей также много обращений с аффиксом принадлежности: кенним 'моя невеста', катым 'мой тесть', бээм 'мой свекор', уругларым авазы букв. 'мать моих детей', уругларым ачазы 'отец моих детей’и др.

Разумеется, взрослые представители родственной группы призывают своих потомков к тому, чтобы поддерживать, укреплять связи со своими родственниками. При этом важное значение они уделяют вопросам правильных терминов тувинского языка. Однако, в ситуации развивающегося и даже меняющегося билингвизма задача сохранения норм тувинского языка становится все более и более сложной.

Исследование терминологии, которую использует лишь одна родственная группа тувинцев, конечно фиксирует лишь одно локальное поле функционирования языка. На нем можно увидеть определенные общетувинские тенденции. Но для того, чтобы получить более полную картину, следует обратиться к исследованиям и других родственных групп тувинцев из разных районов республики. При этом, поскольку языковые процессы проходят в тесной связи с этносоциальными, этнокультурными процессами, полагаем, настало время для объединения усилий и общих исследований как в филологическом плане, так и в этнологическом.

\footnotetext{
${ }^{1}$ Хажики Шенне Викторовна, 1984 г.р., род. в г. Кызыл, проживает в пос. Каа-Хем, Кызылского района.

${ }^{2}$ Ооржак Буян Тас-оолович, 1975 г.р., род. в с. Аянгаты, Барун-Хемчикского района, прож. в г. Кызыл.
} 


\section{СПИСОК ЛИТЕРАТУРЫ}

Бурыкин, А. А., Летягина Н. И. (1999) Терминология родства тувинцев в сравнении с терминами родства других тюркских народов // Алгебра родства. Родство. Система родства. Системы терминов родства. Вып. 4. / отв. ред. В. А. Попов СПб. : Типография Наука РАН. 288 с. С. 180-181.

Бурыкин, А. А., Попов, В. А. (2020) Русская терминология родства и свойства: историческая динамика, аксиологические поля, коммуникативный дискурс. СПб. : Петербургское востоковедение. 320 с.

Вайнштейн, С. И. (1961) Тувинцы-тоджинцы. Историко-этнографические очерки. М. : Изд-во вост. лит. 218 с.

Вайнштейн, С. И. (1969) Личные имена, термины родства и прозвища у тувинцев // Ономастика / отв. ред. В. А. Никонов, А. В. Суперанская. М. : Наука. 382 с. С. 125-132.

Вайнштейн, С. И. (1989) Тувинцы // Системы личных имен у народов мира / отв. ред. М. В. Крюков. М. : Наука. 382 с. С. $305-307$.

Дагылга: тувинские обряды освящения в XXI веке (2021) / под ред. Ч. К. Ламажаа и Н. Д. Сувандии. Кызыл : б. и. $188 \mathrm{c}$.

Кара-оол, Л. С. (2004) Термины родства и свойства в тувинском языке : автореферат дисс. ... к. филол. н. М. 24 с.

Кара-оол, Л. С. (2006) Термины родства и свойства в тувинском языке. Кызыл : РИО ТывГУ. 252 с.

Катанов, Н. Ф. (1903) Опытъ изслъдованія урянхайскаго языка, съ указаніемъ главнъйшихъ родственныхъ отношеній его къ другимъ языкамъ тюркскаго корня. Казань : Типо-литографія Императорскаго Казанскаго Университета. 1600 с.

Кенин-Лопсан, М. Б. (1994) Тыва чоннуң бурунгу ужурлары [Традиционная этика тувинцев]. Кызыл: Институт усовершенствования учителей Республики Тыва; Новости Тувы. 192 с.

Кон, Ф. Я. (1934) За 50 лет : Экспедиция в Сойотию. М. : Изд-во Всес. о-ва поликаторжан и ссыльно-поселенцев. T. 3. 293 c.

Кужугет, Ш. Ю., Сувандии, Н. Д., Дамбаа, Ш. В., Ламажаа, Ч. К. (2019) Концепт төрел 'родственник’ в языковой картине мира тувинцев //Новые исследования Тувы. № 3. C. 149-157.DOI: https://www.doi.org/10.25178/nit.2019.3.12

Куулар, Е. М. (2000) Термины родства юго-восточных тувинцев // Эрдем шинжилгээний ойллого / ред. проф. Б. Катуу. 2 боть. 27 дэвтэр. Ховд : б. и. 175 с. С. 150-154.

Ламажаа, Ч. К. (2021а) Социальная культура тувинцев и онлайн-пространство // Новые исследования Тувы. № 2. C. 115-129. DOI: https://www.doi.org/10.25178/nit.2021.2.10

Ламажаa, Ч. К. (2021b) Тува как лимитрофная зона: язык, религия и идентификация тувинцев // Новые исследования Тувы. № 3. C. 178-194. DOI: https://www.doi.org/10.25178/nit.2021.3.14

Ламажаa, Ч. К. (2021с) Тувинские обряды дагылга в XXI веке // Этнографическое обозрение. № 2. С. $125-143$. DOI: https://doi.org/10.31857/S086954150014811-2

Тувинско-русский словарь (1968): 22000 слов / ред. Э. Р. Тенишев. М. : Советская энциклопедия. 648 с.

Потапов, Л. П. (1969) Очерки народного быта тувинцев. М. : Наука. 402 с.

Степанофф, Ш. (2009) Метаморфозы родства у тувинцев // Этнографические исследования. № 4. С. 129-145.

Чадамба, 3. Б. (2013) Тувинская диалектология и тюркская руника. Абакан : ООО «Журналист». 213 с.

Яковлев, Е. К. (1900) Семейный и общественный быт у сойот: роды, степени родства, брак и положение женщины, развод, население, похороны // Этнографический обзор инородческого населения долины Южного Енисея и объяснительный каталог этнографического отдела музея. Вып. 4. Минусинск : Изд. на средства В. А. Данилова. $357 \mathrm{c}$.

Дата поступления: 05.09.2021 2.

\section{REFERENCES}

Burykin, A. A. and Letyagina, N. I. (1999) Terminologiia rodstva tuvintsev v sravnenii s terminami rodstva drugikh tiurkskikh narodov Iuzhnoi Sibiri [Tuvan kinship terminology in comparison with kinship terms of other South Siberian Turks]. In: Algebra rodstva [Algebra of kinship]. Issue 4 / ed. by V. A. Popov. St. Petersburg, Museum of Anthropology and Ethnography of RAS. 288 p. Pp. 179-196. (In Russ.).

Burykin, A. A. and Popov, V. A. (2020) Russkaia terminologiia rodstva i svoistva: istoricheskaia dinamika, aksiologicheskie polia, kommunikativnyi diskurs [Russian terminology of kinship and affinity: Historical dynamics, axiological fields, communicative discourse]. St. Petersburg, Peterburgskoe vostokovedenie Publ. 320 p. (In Russ.).

Vainshtein, S. I. (1961) Tuvintsy-todzhintsy. Istoriko-etnograficheskie ocherki [Tozhu Tuvans: Historical and ethnographic essays]. Moscow, Nauka Publ. 218 p. (In Russ.). 
Weinstein, S. I. (1969) Lichnye imena, terminy rodstva i prozvishcha u tuvintsev [Personal names, kinship terms and nicknames among Tuvans]. In: Onomastika [Onomastics] / ed. by V. A. Nikonov and A. V. Superanskaia. Moscow, Nauka Publ. 261 p. Pp. 125-132. (In Russ.).

Weinstein, S. I. (1989) Tuvintsy [Tuvans]. In: Sistemy lichnykh imen u narodov mira [Systems of personal names among the peoples of the world] / ed. by M. V. Kriukov et al. Moscow, Nauka Publ. 383 p. Pp. 305-307. (In Russ.).

Dagylga: tuvinskie obriady osviashcheniia v XXI veke [Dagylga: Tuvan rites of consecration in the 21st century] (2021) / ed. by Ch. K. Lamazhaa and N. D. Suvandii. Kyzyl, s. n. 188 p. (In Russ. and Tuv.).

Kara-ool, L. S. (2004) Terminy rodstva i svoistva $v$ tuvinskom yazyke [Kinship and in-law terms in the Tuvan language] : Abstract of the Diss.... Candidate of Philology. Moscow. 24 p. (In Russ.).

Kara-ool, L. S. (2006) Terminy rodstva i svoistva v tuvinskom yazyke [Kinship and in-law terms in the Tuvan language]. Kyzyl, Editorial and Publishing Department at Tuvan State University. 252 p. (In Russ.).

Katanov, N. F. (1903) Opyt izsledovaniia uriankhaiskago iazyka, s ukazaniem glavneishikh rodstvennykh otnoshenii ego $k$ drugim iazykam tiurkskago kornia [An essay on the Uryanghai language, indicating the most important kinship ties between it and the other languages of the Turkic root]. St. Petersburg, Typolithography at Kazan Imperial University. 1600 p. (In Russ.).

Kenin-Lopsan, M. B. (1994) Tyva chonnuњ burungu uzhurlary [Traditional ethics of Tuvans]. Kyzyl, Institute for Teacher Improvement of the Republic of Tuva ; Novosti Tuvy Publ. 192 p. (In Tuv.).

Kon, F. Ya. (1934) Za piat'desiat let [In fifty years] : Collected works : [in 3 vols.]. Moscow : Publishing House of the AllUnion Society of Political Prisoners and Exiled Settlers. Vol. 3: Ekspeditsiia v Soiotiiu [An expedition to Soyotia]. 293 p. (In Russ.).

Kuzhuget, Sh. Yu., Suvandii, N. D., Dambaa, Sh. V. and Lamazhaa, Ch. K. (2019) Kontsept törel 'rodstvennik' v iazykovoi kartine mira tuvintsev [The concept of törel ('relative') in the Tuvan linguistic world picture]. New Research of Tuva, no. 3, pp. 149-157. (In Russ.). DOI: https://doi.org/10.25178/nit.2019.3.12

Kuular, E. M. (2000) Terminy rodstva iugo-vostochnykh tuvintsev [Kinship terms of Southeastern Tuvans]. In: Erdem shinzhilgeenii oillogo [Erdem test reflector] / ed. by B. Katuu. 2 bot'. 27 devter. Khovd, s. n. 175 p. Pp. 150-154. (In Russ.).

Lamazhaa, Ch. K. (2021a) Sotsial'naia kul'tura tuvintsev i onlain-prostranstvo [Social culture of Tuvans and online space]. New Research of Tuva, no. 2, pp. 115-129. (In Russ.). DOI: https://doi.org/10.25178/nit.2021.2.10

Lamazhaa, Ch. K. (2021b) Tuva kak limitrofnaia zona: iazyk, religiia i identifikatsiia naseleniia [Tuva as a limitrophe zone: Language, religion and people’s identity]. New Research of Tuva, no. 3, pp. 178-194 (In Russ.). DOI: https://doi. org/10.25178/nit.2021.3.14

Lamazhaa, Ch. K. (2021c) Tuvinskie obriady dagylga v XXI veke [Tuvan rites Dagylga in the 20th century]. Etnograficheskoe obozrenie, no. 2, pp. 125-143. (In Russ.). DOI: https://doi.org/10.31857/S086954150014811-2

Tuvinsko-russkii slovar' [A Tuvan-Russian dictionary] (1968) : c. 22000 words / ed. by E. R. Tenishev. Moscow, Sovetskaia entsiklopediia Publ. 646 p. (In Russ. and Tuv.).

Potapov, L. P. (1969) Ocherki narodnogo byta tuvintsev [The Tuvans: Sketches of the folk lifestyle and related household activities]. Moscow, Nauka Publ. 402 p. (In Russ.).

Stépanoff, Ch. (2009) Metamorfozy rodstva u tuvintsev [Metamorphoses of kinship among Tuvans]. Etnograficheskoe obozrenie, no. 4, pp. 129-145. (In Russ.).

Chadamba, Z. B. (2013) Tuvinskaia dialektologiia i tiurkskaia runika [Tuvan dialectology and Turkic runic]. Abakan, OOO “Zhurnalist”. 213 p. (In Russ.).

Yakovlev, E. K. (1900) Semeinyi i obshchestvennyi byt u soiot: rody, stepeni rodstva, brak i polozhenie zhenshchiny, razvod, naselenie, pokhorony [Family and social life of the Soyot: Birth, degree of kinship, marriage and status of women, divorce, population and funeral]. In: Yakovlev, E. K. Etnograficheskii obzor inorodcheskogo naseleniia doliny Yuzhnogo Eniseia i ob"iasnitel'nyi katalog etnograficheskogo otdela muzeia [An ethnographic review of the South Yenisei Valley and the explanatory catalogue of the Museum's Ethnography Research Department]. Minusinsk, V. I. Kornakov's Printing House. 357 p. Pp. 79-99. (In Russ.). 